\title{
18. PALEOMAGNETIC RESULTS OF BASALT SAMPLES FROM DSDP LEG 26, SOUTHERN INDIAN OCEAN ${ }^{1}$
}

\author{
John W. Peirce, Woods Hole Oceanographic Institution, Woods Hole, Massachusetts and Massachusetts Institute of \\ Technology, Cambridge, Massachusetts \\ and \\ Charles R. Denham and Bruce P. Luyendyk ${ }^{2}$, Woods Hole Oceanographic Institution, Woods Hole, Massachusetts
}

\begin{abstract}
Magnetic measurements were made on 67 basalt samples from Sites 250, 251, 253, 254, 256, and 257 of Leg 26, Deep Sea Drilling Project. Paleolatitudes estimated from the inclinations after alternating-field demagnetization at 100 oe are compatible with apparent polar wandering curves (except Site 256) and reconstructions of the Indian Ocean based on lineated magnetic anomalies (except Sites 250 and 256). The samples displayed low coercivities (95-oe average median destructive field), except at Site 254 (383-oe median destructive field). Intensities of natural remanent magnetization are lower than are typical of dredged basalts, and low-field susceptibilities are higher. Viscous remanent magnetization was shown experimentally to be high in many specimens and could account for a large portion of their original intensity. Low coercivities, high viscous remanence, and the limited number of flows sampled all detract from the statistical confidence of the paleolatitude estimates. Site 257 revealed a polarity reversal, which can most likely be attributed to a thin dike or sill injected during a reversed episode subsequent to the emplacement and cooling of the rest of the cored section, which is normally polarized.
\end{abstract}

\section{INTRODUCTION}

Since the tectonic motions of the plates in the Indian Ocean were both rapid and extensive and as they are not yet well understood east of the Ninetyeast Ridge, reliable paleolatitude determinations from there would be valuable. Leg 26 of the Deep Sea Drilling Project recovered long sections of cored basalt from six sites in the Indian Ocean, providing the first opportunity to analyze paleomagnetic variations and properties with depth. Unfortunately, each site probably sampled only a small number of flows, thus leaving the paleolatitude estimates open to considerable interpretation. Nevertheless, paleomagnetic latitudes at Sites 251, 253, 254, and 257 are compatible with reconstructions of the Indian Ocean based on lineated magnetic anomalies (McKenzie and Sclater, 1971; Sclater and Fisher, in press).

Measurements of remanent magnetization were made on 67 samples (72 specimens) from Sites 250, 251, 253, 254,256 , and 257 . Twenty-nine specimens were progressively demagnetized in alternating fields to less than $25 \%$ of their natural remanent magnetization (NRM) in\footnotetext{
2968.

'Woods Hole Oceanographic Institution Contribution Number ${ }^{2}$ Now at University of California, Santa Barbara, California.
}

tensity, and a test for viscous remanent magnetization (VRM) was conducted using 20 specimens. Paleolatitude estimates, based on the geocentric dipole assumption, were made using the magnetic inclinations after cleaning in a peak alternating field of $100 \mathrm{oe}$.

The following abbreviations for paleomagnetic terms are used in this report: AF, alternating field; G, Gauss (emu/cc); H100, AF demagnetized at $100 \mathrm{oe} ; J_{\text {nrm }}$, intensity of NRM; MDF, median destructive field; NRM, natural remanent magnetization; oe, oersteds; $S$, magnetic viscosity coefficient; $S / J_{\text {nrm }}$, normalized viscosity coefficient; SRM, shock remanent magnetization; $T_{c}$, Curie temperature; VGP, virtual geomagnetic pole; VRM, viscous remanent magnetization.

\section{NATURAL REMANENT MAGNETIZATION, COERCIVITY, AND SUSCEPTIBILITY}

Specimen magnetizations were measured on a spinner magnetometer with coil pickup (Phillips and Kuckes, 1967) operated at $9.5 \mathrm{~Hz}$ and $97.5 \mathrm{~Hz}$. A Princeton Applied Research SM-2 spinner magnetometer, operated at $15 \mathrm{~Hz}$, was used for a few oversize specimens. Intensities of NRM ranged from $3.9 \times 10^{-4} \mathrm{G}$ to $4.33 \times 10^{-2} \mathrm{G}$, the geometric mean for all samples being $3.22 \times 10^{-3} \mathrm{G}$ (Table 1). These values are comparable to those previously reported for DSDP basalts, but are somewhat lower than typical values for dredged basalts (Lowrie et al., 1973). 
TABLE 1

Paleomagnetic Results from Basalt Samples, DSDP, Leg 26

\begin{tabular}{|c|c|c|c|c|c|c|c|}
\hline $\begin{array}{c}\text { Sample } \\
\text { (Interval in cm) }\end{array}$ & $\begin{array}{l}\text { NRM } \\
\text { Incl. }\end{array}$ & $\begin{array}{c}\mathrm{H} 100 \\
\text { Incl. }\end{array}$ & $\underset{\left(10^{-4} \mathrm{G}\right)}{J \mathrm{nrm}}$ & MDF & $S / J \mathrm{nrm}(\%)$ & $\left(10^{-4} \mathrm{G} / \mathrm{oe}\right)$ & Remarks \\
\hline \multicolumn{8}{|c|}{ Site $250\left(33.46^{\circ} \mathrm{S}, 39.37^{\circ} \mathrm{E}\right)$} \\
\hline $\begin{array}{l}25-2,140 \\
26-2,140 \\
26-3,16 \\
26-4,09 \\
26-5,115 \\
26-6,58\end{array}$ & $\begin{array}{l}-77.0 \\
-77.3 \\
-65.5 \\
-71.5 \\
-70.7 \\
-84.4\end{array}$ & $\begin{array}{l}-76.2 \\
-62.7 \\
-59.1 \\
-67.5 \\
-68.6 \\
-70.0\end{array}$ & $\begin{array}{l}108 \\
131 \\
153 \\
89.3 \\
88.3 \\
73.5\end{array}$ & $\begin{array}{c}- \\
- \\
- \\
40\end{array}$ & $\begin{array}{l}2 . \\
- \\
- \\
-\end{array}$ & $\begin{array}{r}9.3 \\
12.9 \\
7.5 \\
11.8 \\
10.9 \\
13.4\end{array}$ & \\
\hline \multicolumn{8}{|c|}{ Site $251\left(36.50^{\circ} \mathrm{S}, 49.48^{\circ} \mathrm{E}\right)$} \\
\hline $\begin{array}{l}31-2,84 \\
31-3,50 \\
31-4,48 \\
31-5,105\end{array}$ & $\begin{array}{l}-67.5 \\
-72.2 \\
-26.1 \\
-69.8\end{array}$ & $\begin{array}{l}-52.8 \\
-50.5 \\
-20.2 \\
-66.9\end{array}$ & $\begin{array}{r}21.6 \\
46.1 \\
7.7 \\
104\end{array}$ & $\begin{array}{r}72 \\
40 \\
140 \\
75\end{array}$ & $\begin{array}{r}1.1 \\
1.6 \\
8.6 \\
.3\end{array}$ & $\begin{array}{r}3.5 \\
19.7 \\
13.2 \\
10.4\end{array}$ & High VRM \\
\hline \multicolumn{8}{|c|}{ Site $253\left(24.88^{\circ} \mathrm{S}, 87.37^{\circ} \mathrm{E}\right)$} \\
\hline $58-175 \mathrm{CC}$ & -62.4 & -68.5 & 8.8 & 145 & 2.2 & 31.1 & $\begin{array}{l}\text { Incls., } J \text { nrm, } k \\
\text { mean of } 3 \text { spec. }\end{array}$ \\
\hline \multicolumn{8}{|c|}{ Site $254\left(30.97^{\circ} \mathrm{S}, 87.90^{\circ} \mathrm{E}\right)$} \\
\hline $\begin{array}{l}31-1,111 \\
35-1,54 \\
35-1,107 \\
35-2,40 \\
35-3,23 \\
35-3,110 \\
36-2,30 \\
36-3,25 \\
36-3,105\end{array}$ & $\begin{array}{l}-2.7 \\
+62.2 \\
+70.6 \\
+54.6 \\
+74.8 \\
+54.6 \\
+63.8 \\
+64.4 \\
+66.6\end{array}$ & $\begin{array}{l}+70.2 \\
+61.5 \\
+68.9 \\
+67.0 \\
+70.9 \\
+60.1 \\
+63.9 \\
+64.1 \\
+66.1\end{array}$ & $\begin{array}{r}4.0 \\
11.9 \\
3.9 \\
4.1 \\
15.4 \\
22.3 \\
39.4 \\
21.4 \\
19.7\end{array}$ & $\begin{array}{c}370 \\
- \\
350 \\
- \\
- \\
- \\
- \\
430\end{array}$ & $\begin{array}{c}6.0 \\
- \\
3.6 \\
- \\
- \\
- \\
- \\
- \\
.2\end{array}$ & $\begin{array}{l}1.9 \\
4.3 \\
4.4 \\
5.5 \\
6.4 \\
9.4 \\
6.9 \\
6.8 \\
8.5\end{array}$ & High VRM \\
\hline \multicolumn{8}{|c|}{ Site $256\left(23.46^{\circ} \mathrm{S}, 100.77^{\circ} \mathrm{E}\right)$} \\
\hline $\begin{array}{c}9-2,12 \\
9-2,130 \\
9-3,35 \\
9-3,129 \\
10-2,68 \\
10-2,140 \\
10-2,145 \\
10-3,31 \\
10-3,85 \\
10-3,140 \\
10-4,15 \\
10-4,64 \\
11-1,15 \\
11-1,122 \\
11-2,15 \\
11-2,88 \\
11-3,15\end{array}$ & $\begin{array}{r}-48.7 \\
-64.7 \\
-56.0 \\
-19.2 \\
+50.1 \\
-52.8 \\
-67.5 \\
-49.0 \\
+77.1 \\
+51.4 \\
+20.6 \\
+24.9 \\
-45.0 \\
-57.8 \\
-64.4 \\
-57.9 \\
+12.6\end{array}$ & $\begin{array}{l}-52.3 \\
-56.0 \\
-53.3 \\
-49.2 \\
-40.4 \\
-50.4 \\
-60.7 \\
-52.1 \\
+64.1 \\
+59.5 \\
-42.7 \\
-45.7 \\
-58.2 \\
-41.5 \\
-48.5 \\
-61.3 \\
-53.5\end{array}$ & $\begin{array}{c}56.5 \\
46.8 \\
16.2 \\
92.0 \\
33.6 \\
94.5 \\
131 \\
110 \\
19.7 \\
106 \\
26.1 \\
29.8 \\
187 \\
35.2 \\
37.4 \\
433 \\
34.6\end{array}$ & $\begin{array}{r}110 \\
- \\
- \\
- \\
30 \\
- \\
- \\
- \\
? \\
- \\
- \\
60 \\
- \\
- \\
- \\
120\end{array}$ & $\begin{array}{c}.5 \\
- \\
- \\
? \\
- \\
- \\
- \\
29.0 \\
- \\
- \\
- \\
1.8 \\
- \\
- \\
7.8\end{array}$ & $\begin{array}{l}12.1 \\
10.8 \\
29.2 \\
35.7 \\
40.3 \\
41.7 \\
36.9 \\
39.2 \\
41.4 \\
-. \\
35.3 \\
22.9 \\
40.6 \\
41.8 \\
35.7 \\
25.3 \\
33.9\end{array}$ & $\begin{array}{l}\text { Poor stability } \\
\text { Poor stability } \\
\text { Poor stability } \\
\text { High VRM }\end{array}$ \\
\hline \multicolumn{8}{|c|}{ Site $257\left(30.99^{\circ} \mathrm{S}, 108.35^{\circ} \mathrm{E}\right)$} \\
\hline $\begin{array}{l}11-2,74 \\
11-3,130 \\
12-1,130 \\
12-2,140 \\
12-3,85 \\
13-2,80 \\
13-2,88 \\
13-2,120 \\
13-2,137 \\
13-3,15 \\
13-3,20 \\
13-3,40 \\
13-3,56\end{array}$ & $\begin{array}{l}-49.2 \\
-67.2 \\
-61.6 \\
-74.5 \\
-67.6 \\
-38.1 \\
-54.9 \\
-44.0 \\
-40.3 \\
+47.0 \\
+48.3 \\
-36.5 \\
-38.7\end{array}$ & $\begin{array}{l}-52.9 \\
-70.5 \\
-63.6 \\
-69.7 \\
-68.1 \\
-46.0 \\
-57.9 \\
-44.6 \\
-46.0 \\
+45.5 \\
+46.6 \\
-35.1 \\
-37.6\end{array}$ & $\begin{array}{l}22.7 \\
21.1 \\
23.7 \\
28.1 \\
68.0 \\
21.9 \\
44.6 \\
44.9 \\
15.8 \\
20.7 \\
34.3 \\
45.2 \\
57.9\end{array}$ & $\begin{array}{c}130 \\
135 \\
125 \\
- \\
100 \\
- \\
- \\
- \\
75 \\
- \\
- \\
-\end{array}$ & $\begin{array}{l}2.0 \\
- \\
- \\
- \\
- \\
- \\
- \\
- \\
- \\
- \\
-\end{array}$ & $\begin{array}{r}13.4 \\
9.0 \\
7.9 \\
9.3 \\
12.2 \\
19.7 \\
17.8 \\
14.9 \\
19.3 \\
18.6 \\
18.8 \\
18.7 \\
18.3 \\
\end{array}$ & Mean of 2 spec. \\
\hline
\end{tabular}


TABLE 1 - Continued

\begin{tabular}{|c|c|c|c|c|c|c|c|}
\hline $\begin{array}{c}\text { Sample } \\
\text { (Interval in } \mathrm{cm} \text { ) }\end{array}$ & $\begin{array}{l}\text { NRM } \\
\text { Incl. }\end{array}$ & $\begin{array}{c}\mathrm{H} 100 \\
\text { Incl. }\end{array}$ & $\underset{\left(10^{-4} \mathrm{G}\right)}{J \text { nrm }}$ & MDF & $S / J$ nrm (\%) & $\left(10^{-4} \mathrm{G} /\right.$ oe $)$ & Remarks \\
\hline $13-3,80$ & -50.0 & -48.1 & 25.0 & - & - & - & \\
\hline $13-3,103$ & -46.0 & -39.7 & 41.6 & - & - & 18.8 & \\
\hline $13-3,124$ & -21.5 & -36.9 & 45.7 & - & - & 15.4 & \\
\hline $13-4,62$ & -31.3 & -51.9 & 12.3 & - & - & 20.2 & \\
\hline $14-2,95$ & -31.7 & -34.8 & 11.8 & - & - & 17.8 & \\
\hline $14-3,73$ & -48.9 & -59.2 & 23.9 & - & - & 19.7 & \\
\hline $14-4,111$ & -42.4 & -61.3 & 51.7 & 65 & 5.2 & 42.2 & High VRM \\
\hline $14-5,95$ & -66.1 & -67.4 & 22.8 & - & - & 12.7 & \\
\hline \multicolumn{8}{|c|}{ Site $257\left(30.99^{\circ} \mathrm{S}, 108.35^{\circ} \mathrm{E}\right)$} \\
\hline $15-1,133$ & -60.7 & -68.1 & 50.4 & 70 & - & 19.2 & Mean of 2 spec. \\
\hline $15-2,111$ & -70.2 & -71.3 & 23.7 & - & - & 14.1 & \\
\hline $16-1,124$ & -67.9 & -68.6 & 36.0 & - & - & 14.8 & \\
\hline $16-2,145$ & -48.6 & -61.8 & 17.4 & 130 & $-\cdot$ & 15.9 & Mean of 2 spec. \\
\hline $16-3,73$ & -65.0 & -70.2 & 33.1 & - & - & 20.1 & \\
\hline $17-1,86$ & -67.5 & -71.1 & 45.0 & 140 & 1.0 & 21.8 & H200 Incl. \\
\hline $17-2,60$ & -65.0 & -66.2 & 19.9 & - & - & 13.9 & \\
\hline $17-4,145$ & -67.7 & -68.6 & 12.1 & - & - & 16.4 & \\
\hline $17-5,130$ & -69.1 & -71.2 & 80.7 & 120 & 2.7 & 18.5 & H200 Incl. \\
\hline
\end{tabular}

An alternating field (AF) demagnetizing apparatus with two-axis tumbler and ambient field cancellation to less than $5 \times 10^{-3}$ oe was used for magnetic cleaning. During progressive AF demagnetization, the magnetization directions usually stabilized after cleaning in a 100 -oe peak field.

Except at Site 254, all the specimens which were progressively demagnetized exhibited low coercivities, their MDF's averaging 95 oe for 20 specimens (Table 1). In most of the samples, Ade-Hall (this volume, Chapter 19) found little altered, single-phase titanomagnetite, whose coarse grain size appears to control the coercivity. However, at Site 257, hematite is also present in several samples, contributing to higher MDF and lower NRM intensity (Figure 1).

Only samples from Site 254 show evidence of significant deuteric oxidation. Ade-Hall (this volume, Chapter 20 ) found exsolved lathes of ilmenite within grains of low-titanium titanomagnetite. The ilmenite divides the titanomagnetite into finer grains, accounting for the high average MDF of 383 at this site.

Low-field magnetic susceptibilities, measured with a Geophysical Specialties bridge, are higher than those for dredged basalts (Fox and Opdyke, 1973) and for previously reported DSDP basalts (Lowrie et al., 1973; Lowrie and Opdyke, 1972, 1973). There is considerable variation between sites, ranging from an arithmetic mean of $6.0 \times 10^{-4} \mathrm{G} / \mathrm{oe}$ at Site 254 to one of 32.7 $\times 10^{-4} \mathrm{G} /$ oe at Site 256 (Table 1).

\section{VISCOUS REMANENT MAGNETIZATION}

When demagnetized in a peak field of $25-50$ oe, most of the normally polarized specimens showed an increase of about 5\% in intensity (Figures 2-7), accompanied by a slight increase in inclination. This effect is attributed to the addition of an oppositely inclined component of VRM, acquired during upright storage in the northern hemisphere, to the NRM component acquired in the southern hemisphere.
An experiment with VRM, similar to that described by Lowrie (1973), was conducted on 20 specimens to evaluate the materials for paleomagnetic purposes. Each specimen was first demagnetized until less than $10 \%$ of its NRM remained. It was then placed in a constant orientation in the earth's field, and its magnetization was measured over a period of 1000 hours at 8-10 logarithmically spaced times. The VRM accumulated since the beginning of the experiment was plotted against the logarithm of time in hours, and the magnetic viscosity coefficient $(S)$ was determined from the slope of the least-squares best-fitting line (Figures 8-11). $S$ ranged from 0.2 to $29 \%$ of $J_{\text {nrm }}$ (Table 1) for a 10 -fold increase in time, implying possible VRM acquisition during the Brunhes normal epoch of $2-290 \%$ (see captions of Figures 8-11). An AF of about 100 oe was sufficient for removing an amount equivalent to the inferred Brunhes VRM in all but Site 254 specimens. Site 254 directions showed very little change between 100 and 1300 oe cleaning, indicating that any VRM component had been removed by $100 \mathrm{oe}$. We found generally high levels of VRM, which may complicate the interpretation of marine magnetic anomalies near Leg 26 sites. On the other hand, the specimens may be reliable paleolatitude indicators provided measures are taken to minimize both long and short-term VRM. We found that measurable amounts of VRM could be acquired over the period of a single measurement, especially at Site 256 , where we assign a low reliability because of this behavior.

Two samples were rejected from the paleolatitude calculations as a result of the VRM test. The normalized viscosity coefficient, $S / J_{\mathrm{nrm}}$, was very high at $8.6 \%$ for Sample 251A-31-4-48, whose direction differed radically from the other directions at the same site. Specimen $256-10-3-085$, with $S / J_{\text {nrm }}$ of $29 \%$, was rejected because the intensities during AF demagnetization were so unstable that a demagnetization curve could not be drawn beyond 50-oe peak field. 

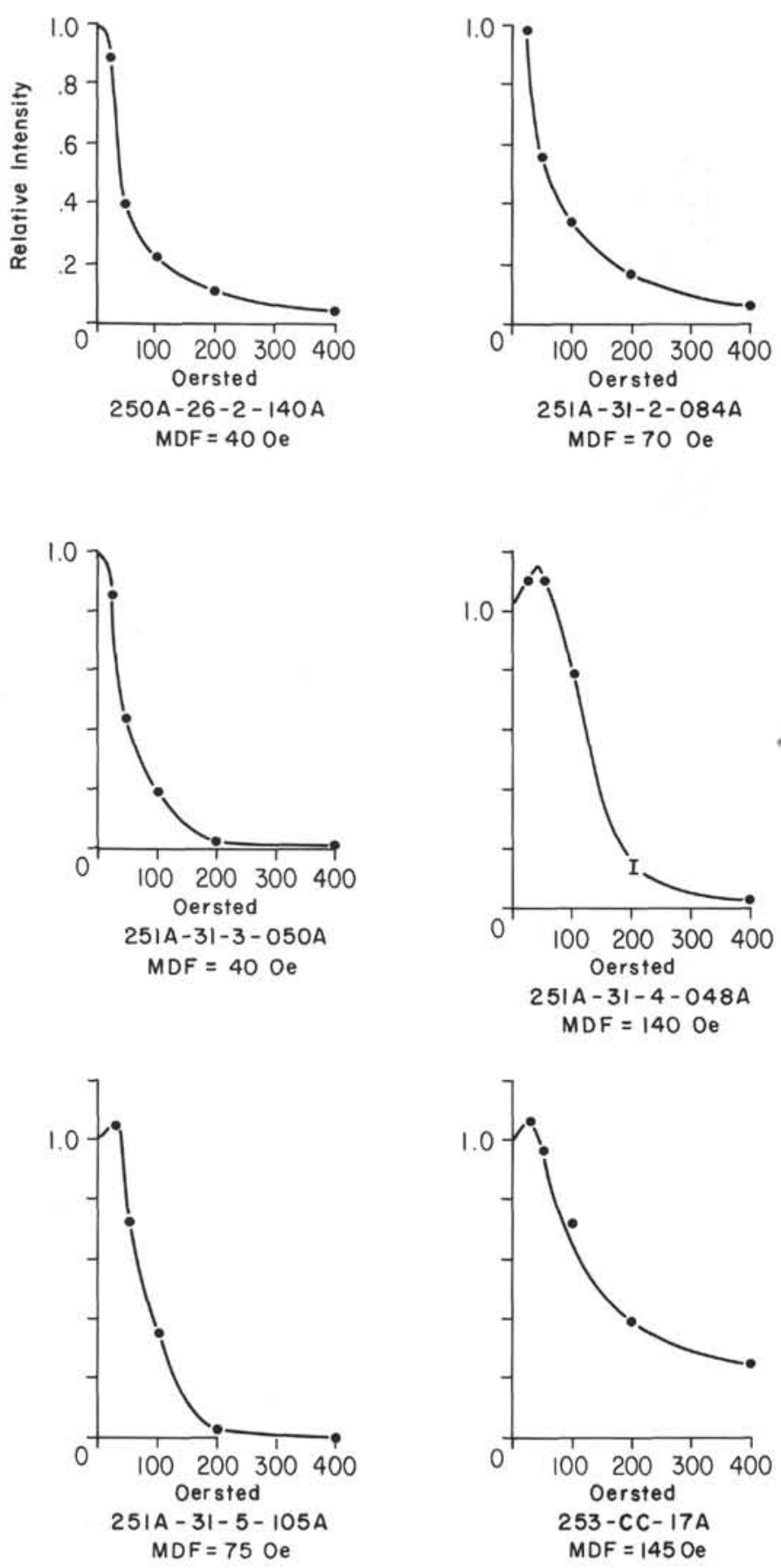

Figure 1. Progressive AF demagnetization curves for DSDP Leg 26 basalt specimens. Intensities are relative to the untreated (NRM) values. Replicate demagnetization and measurements are connected by vertical bars.

Samples 254-31-1-111 and 256-11-3-15, which also displayed high viscosity coefficients, were not rejected, since their magnetic directions moved rapidly at low cleaning fields and stabilized near the 100-oe position, indicating that the large VRM component had been satisfactorily removed.

To supplement the VRM tests, two specimens were tested for the acquisition of shock remanent mag-
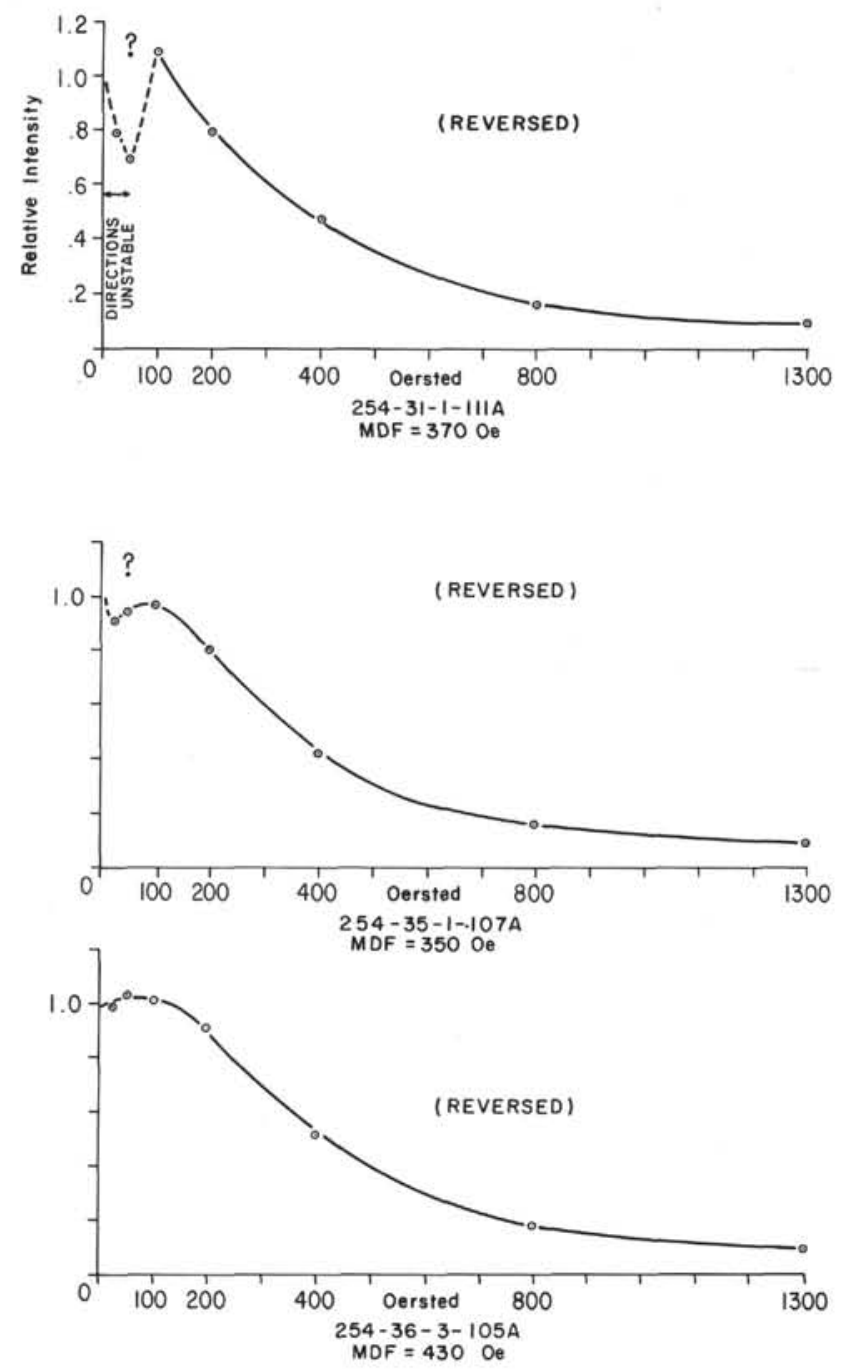

Figure 2. Progressive $A F$ demagnetization curves for DSDP Leg 26 basalt specimens. Intensities are relative to the untreated (NRM) values. Replicate demagnetization and measurements are connected by vertical bars.

netization (SRM). While held in a known orientation, each was given a tap with a screwdriver, whose local field was about 0.5 oe. Both specimens displayed immediate changes in intensity (Figures 12 and 13), amounting to about $5 \%$ of NRM and oriented along the direction of the applied earth's field, similar to the behavior observed by Nagata (1971). Since it is difficult to assess the intensity and stability of SRM acquired during DSDP drilling, recovery, and storage operations, we have assumed that its influence is weak in specimens demagnetized in peak alternating fields of 100 oe or higher.

\section{INCLINATIONS AND REVERSALS}

The correlation between the polarity of the samples (Figure 14, Table 1) and the polarity of the oceanic magnetic anomalies at the drill sites was poor. Site 250 was drilled on a negative anomaly, yet the samples all had normal inclinations. Conversely, Site 254 samples had very stable reversed inclinations, yet the site lay over a positive anomaly. The positive anomalies at Sites 256 

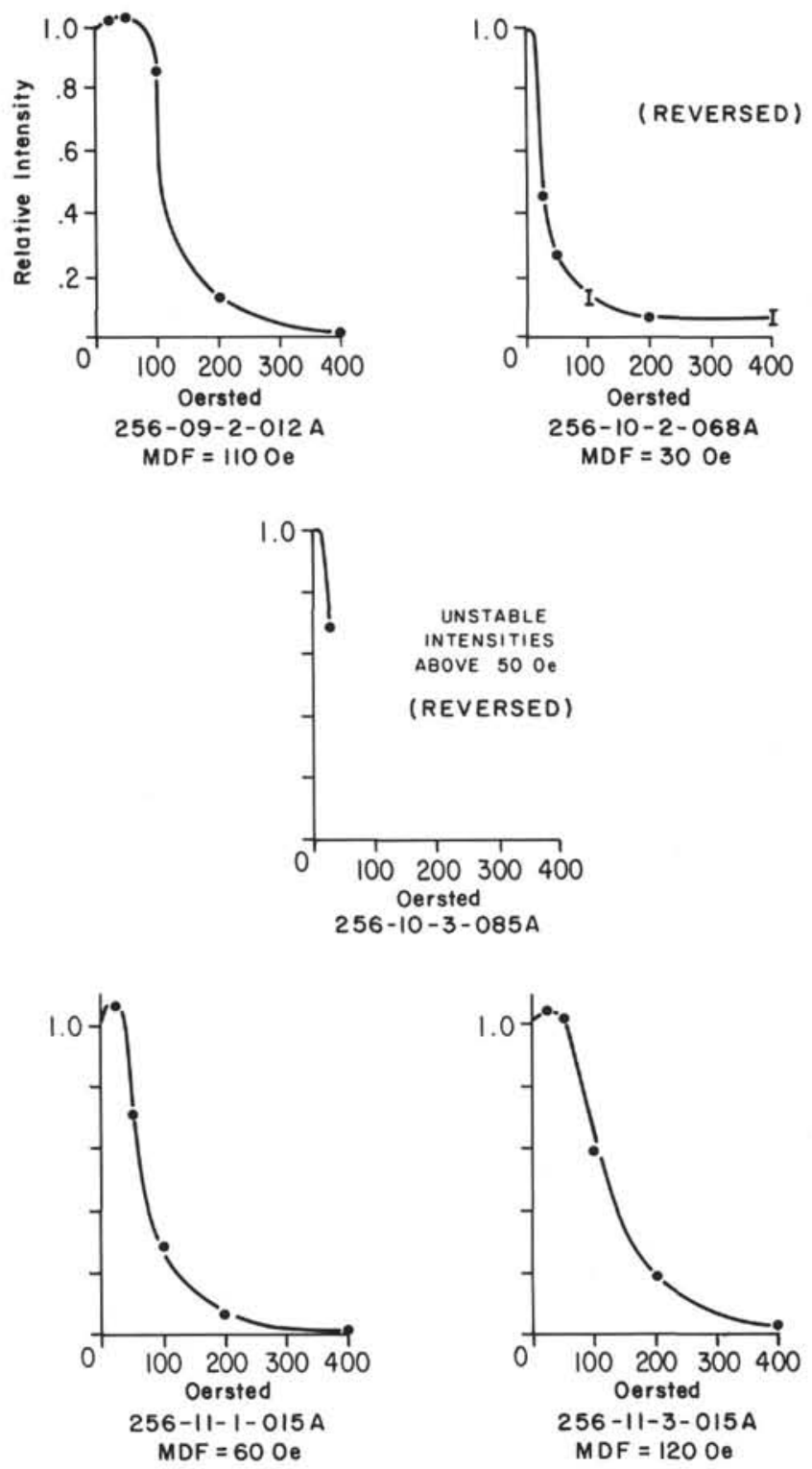

Figure 3. Progressive AF demagnetization curves for DSDP Leg 26 basalt specimens. Intensities are relative to the untreated (NRM) values. Replicate demagnetization and measurements are connected by vertical bars.

and 257 correlate with the predominantly normal inclinations found there. Sites 251 and 253 lay over anomalies of indeterminate polarity, and their samples had normal inclinations. If the classic sea-floorspreading model applies, then Site 250 could have been located over lavas deposited during a short polarity event, whose extent is too small to be observed in the surface anomaly pattern. At Site 254 on the Ninetyeast Ridge, a simple block model does not apply to the anomaly, and a large mass of normally magnetized rock may lie beneath the drilled section.

At Site 256, we found a cluster of reversed NRM inclinations in Core 10, Sections 2 to 4 , as well as another shallow reversed inclination at the bottom of the hole. After cleaning in 100-oe peak alternating field,
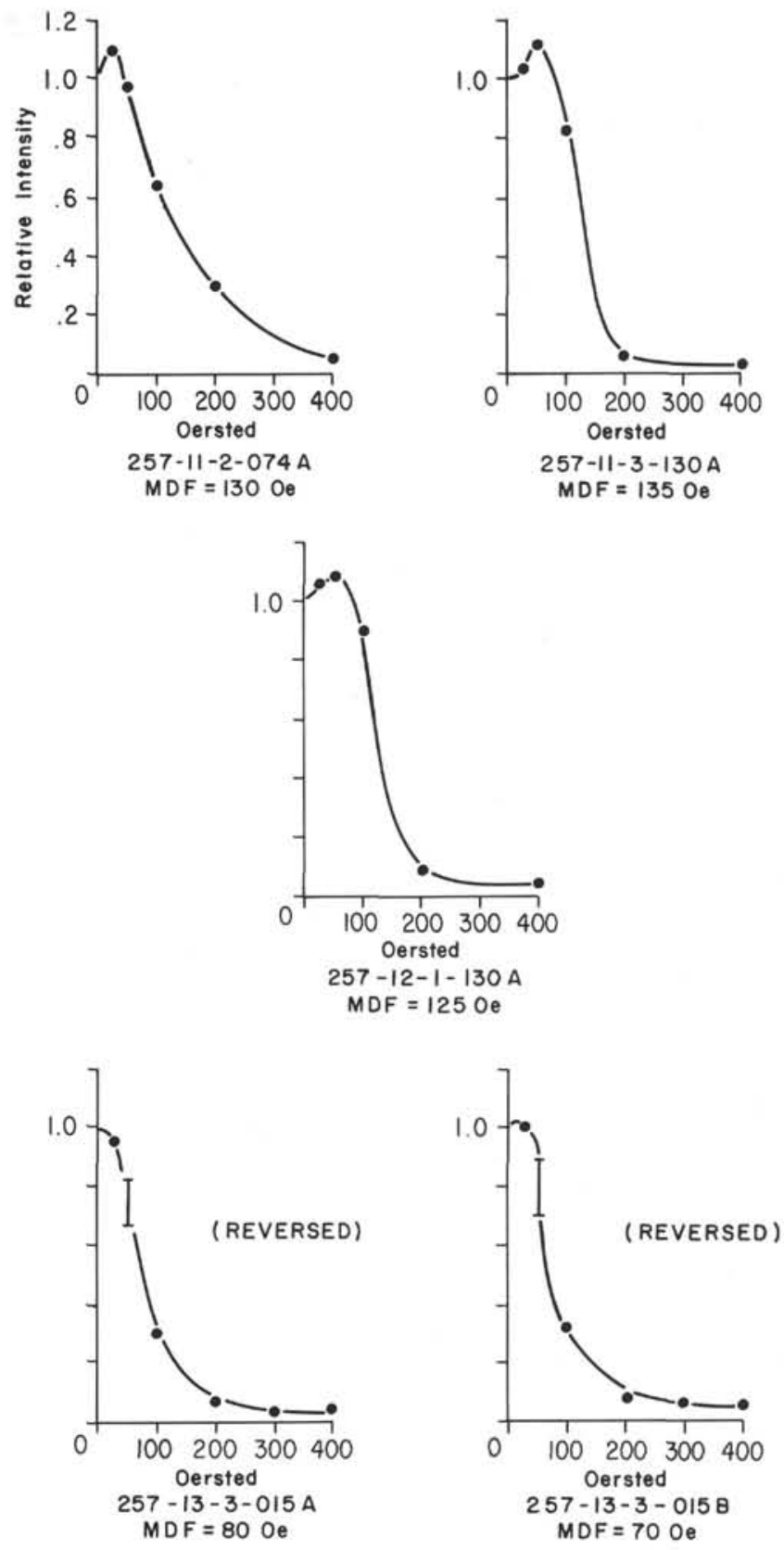

Figure 4. Progressive AF demagnetization curves for DSDP Leg 26 basalt specimens. Intensities are relative to the untreated (NRM) values. Replicate demagnetization and measurements are connected by vertical bars.

only two samples remained reversed. One of these, Sample $10-3-85$, varied erratically in intensity when progressively demagnetized, and it was highly effected by VRM $\left(S / J_{\mathrm{nrm}}=29 \%\right)$. In view of the instability of Sample $10-3-85$, the present data are clearly insufficient to establish the existence of a reversed polarity subzone at this level in the core.

At Site 257, we found that the inclinations have a definite bimodal distribution (Figure 15). As shown in Tables 1 and 2 , the lower inclinations (average $-43.9^{\circ}$ ) are spatially grouped in Core 13, Section 2 to Core 14, 

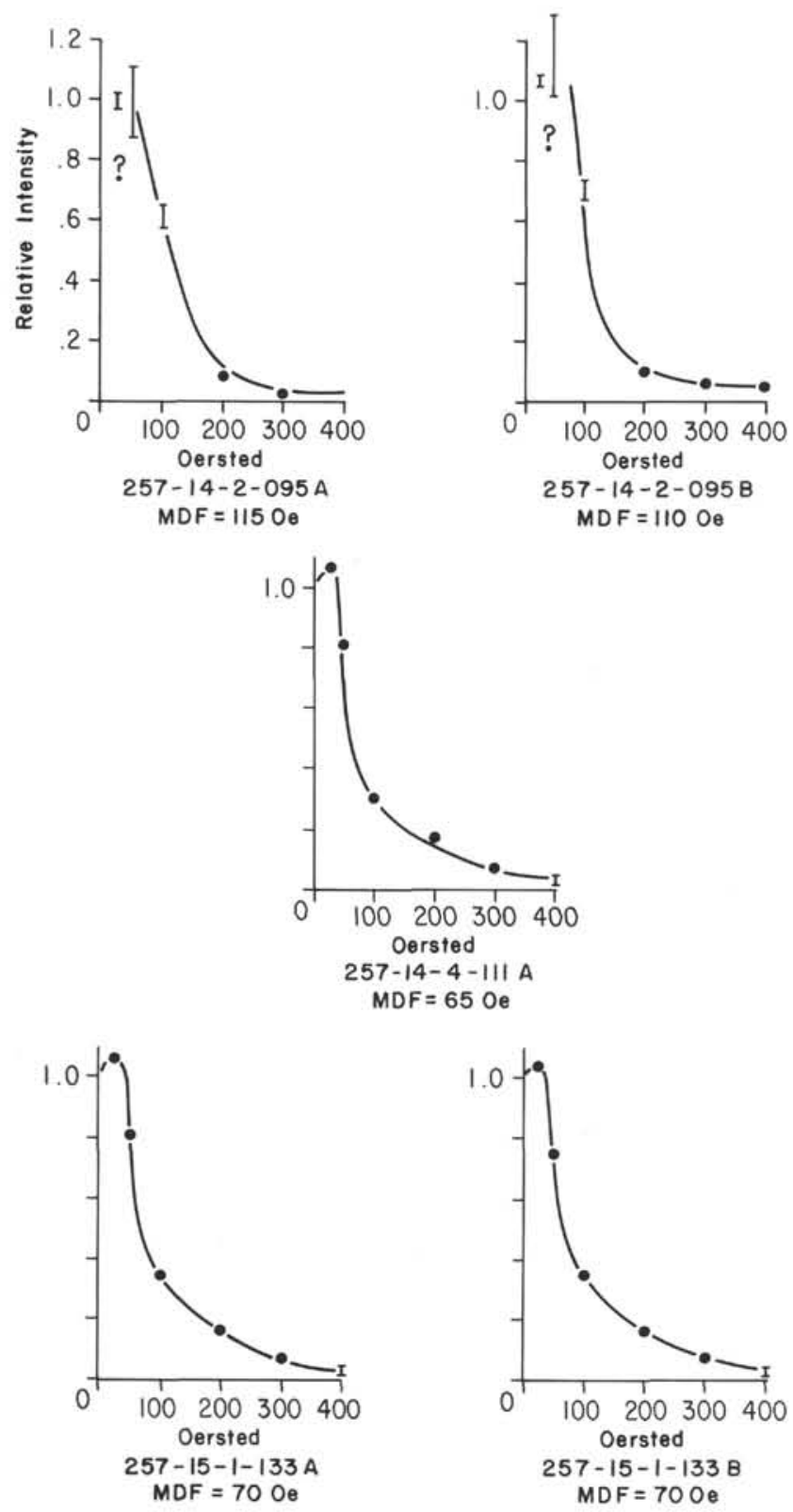

Figure 5. Progressive AF demagnetization curves for DSDP Leg 26 basalt specimens. Intensities are relative to the untreated (NRM) values. Replicate demagnetization and measurements are connected by vertical bars.

Section 2, except for one low inclination at the top of the core. This group includes the two reversed inclinations, which were averaged with opposite signs. Above this group, the mean inclination was $-68.0^{\circ}$, compared with $-67.1^{\circ}$ below it. The difference between the low- and high-inclination groups is equivalent to a difference in paleolatitude of $25^{\circ}$, assuming all had the same declination. Watkins et al. (1972), suggested that the Brunhes secular variation in the Indian Ocean could be modeled by employing an $11.5^{\circ}$ dipole wobble, combined with nondipole behavior comparable to that of the present field. This model could produce a variation of $25^{\circ}$ in apparent paleolatitude if sampled near the extremes of
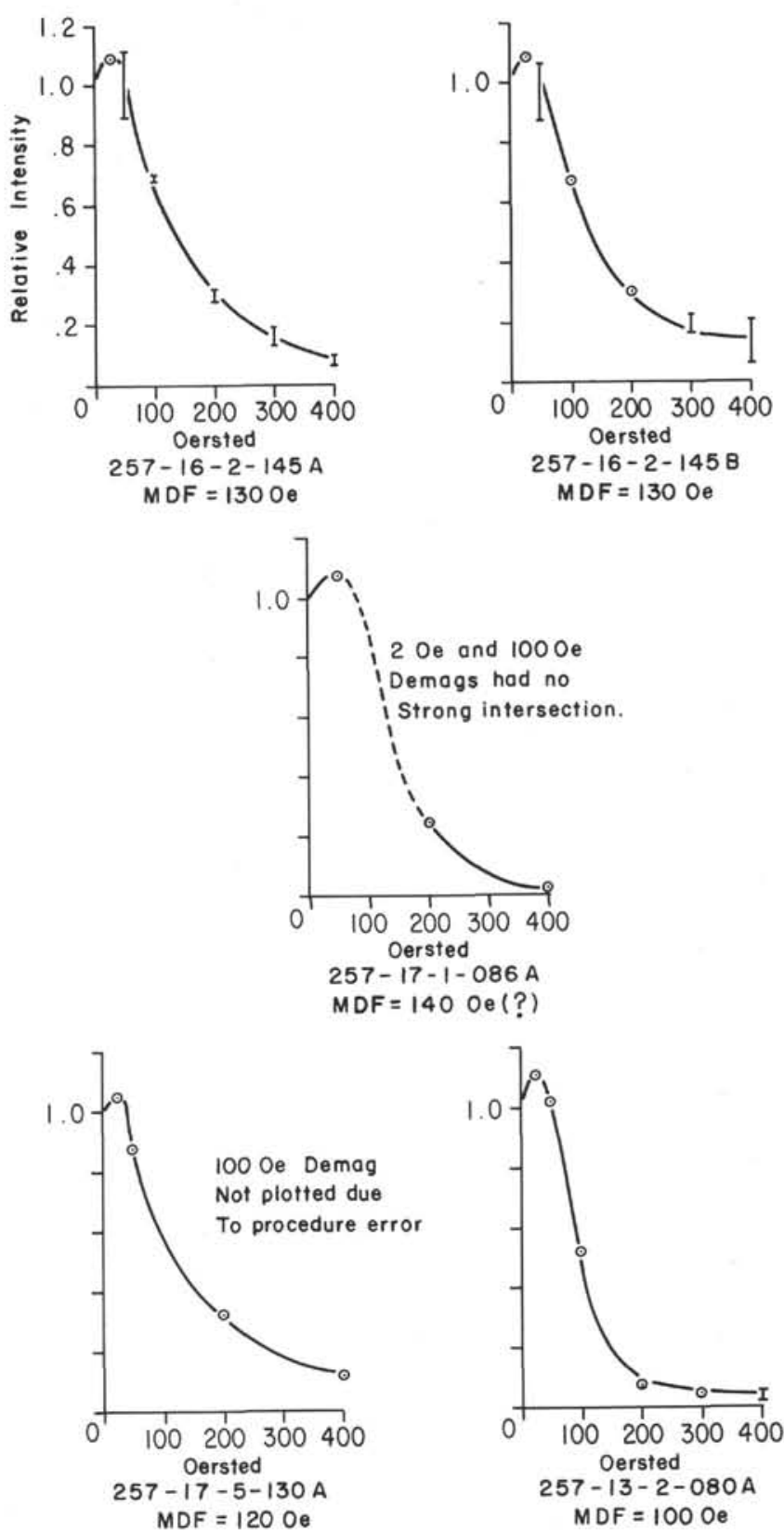

Figure 6. Progressive AF demagnetization curves for DSDP Leg 26 basalt specimens. Intensities are relative to the untreated (NRM) values. Replicate demagnetization and measurements are connected by vertical bars.

the secular variation. Therefore, the difference in inclination may reflect secular variation and suggests that the cored section covers a considerable span of time.

The two reversed samples at Site 257 have inclinations within $2^{\circ}$ of the mean of the group of lower inclinations, suggesting that the reversal is real and not due to local reorientation, such as an overturned block at the front of a flow. In contrast to the reversed samples at Site 256 , these samples were magnetically stable. This is the first instance in which a reversed subzone has been clearly documented from DSDP basalts. The most likely explanation for the narrow reversed zone is that it is a 
MEDIAN DESTRUCTIVE FIELD, CURIE TEMP. AND NRM VS. DEPTH, DSDP SITE 257

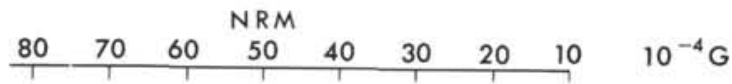

\begin{tabular}{lllllll}
275 & 300 & Tc & & & & \\
125 & 350 & 375 & 400 & ${ }^{\circ} \mathrm{C}$ \\
\hline
\end{tabular}

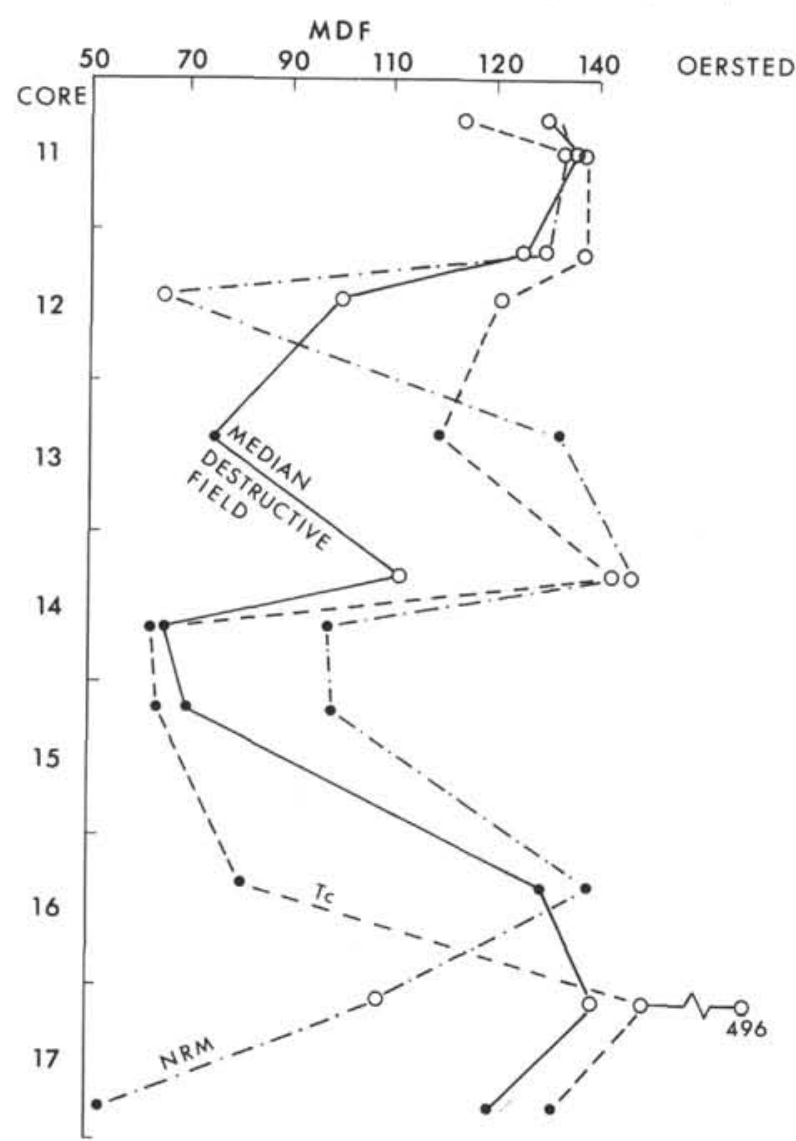

Figure 7. Median destructive field $(M D F)$, Curie temperature $\left(T_{C}\right)$, and NRM intensity at Site 257. Open and closed circles indicate the presence and absence of hematite, respectively. Curie temperatures and hematite determinations are from Ade-Hall this volume, Chapter 20.

dike or sill injected during a reversed polarity event subsequent to the time during which the normally magnetized lavas cooled. On the basis of limited marine magnetic coverage, Site 257 appears not to be located on the boundary between two major blocks of opposite polarity, but it could be near a small block representing a short unseen polarity event. The plate reconstructions of Sclater and Fisher (in press) suggest that the site formed at a spreading center. However, the wide range of preliminary $\mathrm{K} / \mathrm{Ar}$ dates reported by Rundle et al. (this volume, Chapter 17) argues against a spreading center origin for at least part of the cored interval, in which case the reversed subzone would have little significance. There is no evidence (Ade-Hall, this volume, Chapter 19) suggesting magnetic self-reversal of these samples.

\section{PALEOLATITUDES}

Paleomagnetic studies ordinarily assume that the geomagnetic field approximates that of an axially oriented
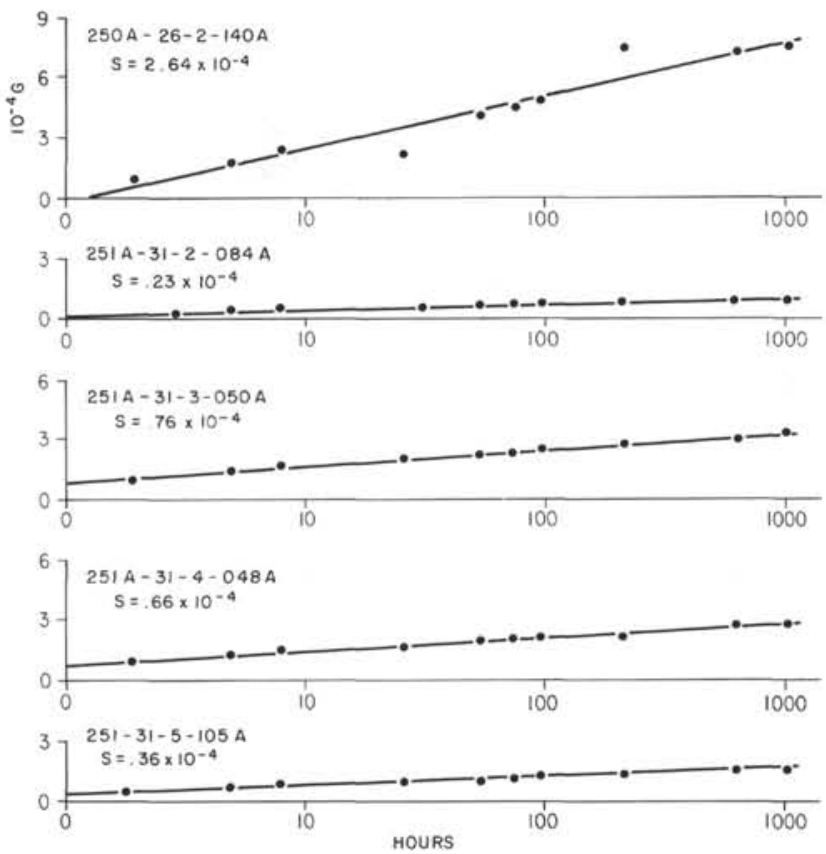

Figure 8. Viscous remanent magnetization (VRM) acquired in the earth's field by initially demagnetized specimens. $V R M$ was calculated as the vectorial difference between the final and initial magnetic remanences. The viscosity coefficient $\mathrm{S}$ is the slope of the least-squares best-fitting line through the VRM data when plotted against the logarithm of time. During the Brunhes epoch, specimens could have acquired VRM equaling 9.78S (9.78=log number of hours in 700,000 years) if the linear extrapolation is valid and initial magnetizations were zero.

geocentric dipole when averaged over a sufficient length of time. Because lavas record the local field direction only at discrete times, the number of flows and the total length of time sampled are vitally important to the statistical confidence which can be ascribed to the data. In the basalt section cored on Leg 26, little information is available about either parameter.

The Leg 26 paleolatitude data can be compared both with published reconstructions for the Indian Ocean and with polar wandering curves. McKenzie and Sclater (1971) and Sclater and Fisher (in press) reconstructed the relative positions of the Indian Ocean continents from sea-floor magnetic data for various times, then rotated the entire set of continents so that the VGP for Australia lay on the South Pole. This gives paleolatitude estimates for the various reconstructions. The data at Sites 250 and 251 on the African plate are limited. The magnetic paleolatitude for Site 250 does not agree with McKenzie and Sclater's (1971) reconstruction for $75 \mathrm{~m} . y$. ago, but compares favorably with the apparent polar wandering curve for Africa, as shown in Figure 16. Site 251 formed near its present latitude, and according to McKenzie and Sclater, did not exist 36 m.y. ago. Our paleolatitude estimate is close to the present latitude, and it is compatible with any age since the middle Tertiary on the polar wandering curve.

On the Ninetyeast Ridge, the single sample from Site 253 bears no statistical significance, but it is not incom- 

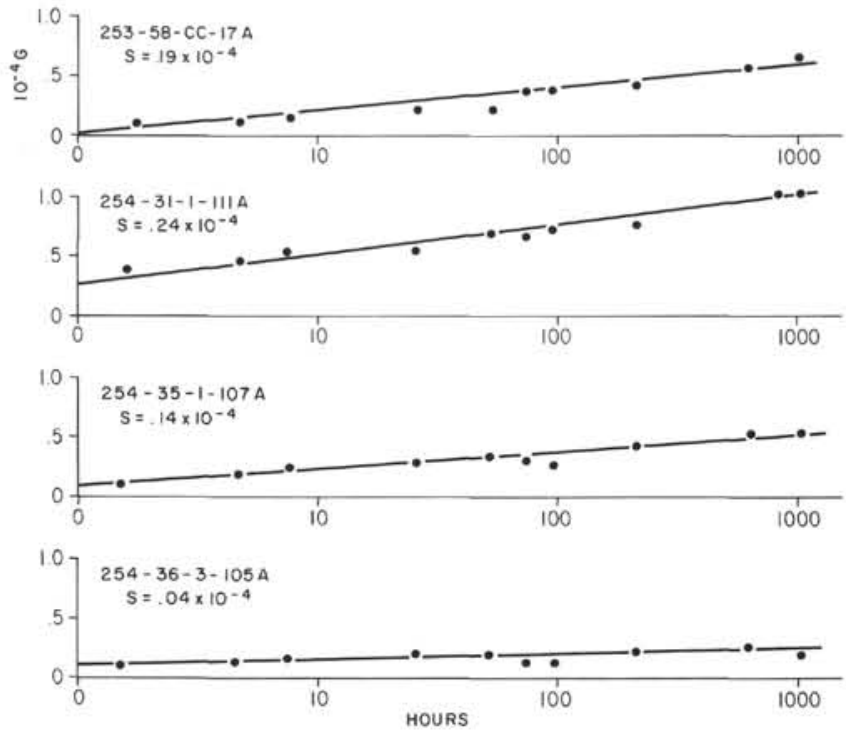

Figure 9. Viscous remanent magnetization (VRM) acquired in the earth's field by initially demagnetized specimens. VRM was calculated as the vectorial difference between the final and initial magnetic remanences. The viscosity coefficient $\mathrm{S}$ is the slope of the least-squares best-fitting line through the VRM data when plotted against the logarithm of time. During the Brunhes epoch, specimens could have acquired VRM equaling 9.78S (9.78=log number of hours in 700,000 years) if the linear extrapolation is valid and initial magnetizations were zero.
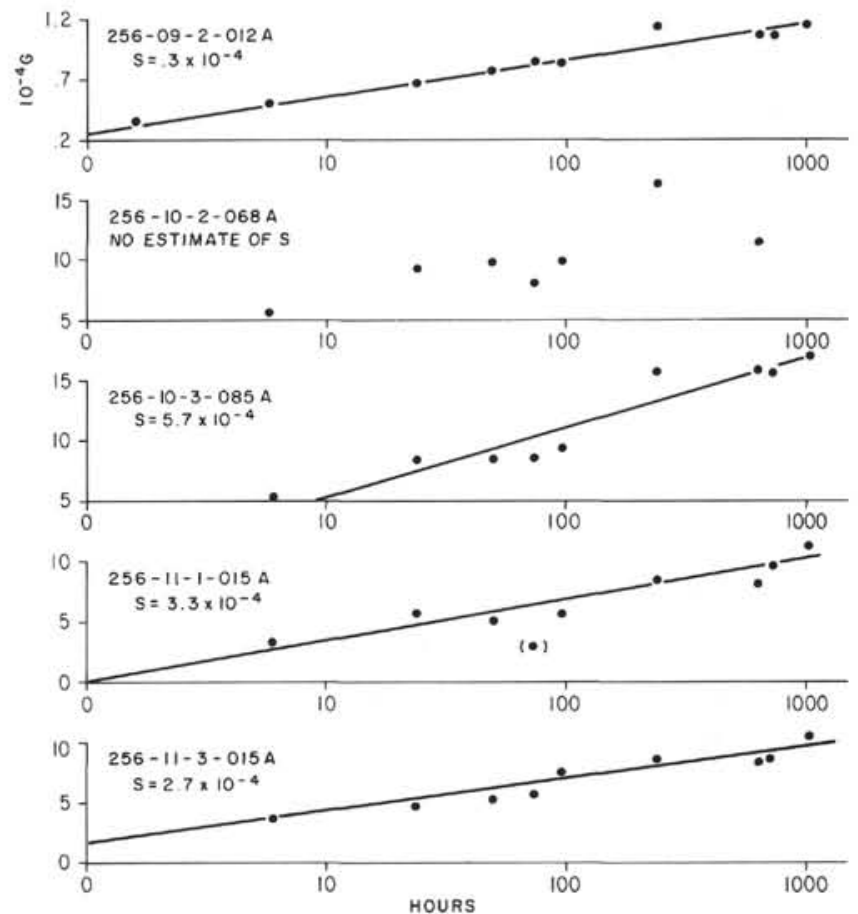

Figure 10. Viscous remanent magnetization (VRM) acquired in the earth's field by initially demagnetized specimens. $V R M$ was calculated as the vectorial difference between the final and initial magnetic remanences. The viscosity coefficient $\mathrm{S}$ is the slope of the least-squares best-fitting line through the VRM data when plotted against the logarithm of time. During the Brunhes epoch, specimens could have acquired VRM equaling 9.78S (9.78=log number of hours in 700,000 years) if the linear extrapolation is valid and initial magnetizations were zero.

TABLE 2

Site Means and Paleolatitudes

\begin{tabular}{llcccccc}
\hline Site & (Plate) & $\mathrm{N}$ & $\begin{array}{c}\text { Mean Incl. } \\
\pm \mathrm{sd}\end{array}$ & $\begin{array}{c}\text { Paleo- } \\
\text { latitude }\end{array}$ & $\begin{array}{c}\text { Site } \\
\text { Latitude }\end{array}$ & $\begin{array}{c}\text { SF Latitude } \\
\text { (Age) }\end{array}$ & $\begin{array}{c}\text { MS Latitude } \\
\text { (Age) }\end{array}$ \\
\hline 250 & (African) & 6 & $-67.4 \pm 6.0$ & -50.2 & -33.5 & - & -36 \\
251 & (African) & 3 & $-56.7 \pm 8.9$ & -37.3 & -36.5 & - & $(75)$ \\
253 & (Indian) & 1 & -68.5 & -51.8 & -24.9 & -45 & - \\
254 & (Indian) & 9 & $+65.9 \pm 3.8$ & -48.2 & -31.0 & -52 & -43 \\
256 & (Australian) & 16 & $-51.6 \pm 6.7$ & -32.2 & -23.5 & -39 & -45 \\
257 & (Australian) & 21 & $-62.2 \pm 10.5$ & -43.5 & -31.0 & -48 & $(36)$ \\
& & & & & & $(100)$ & -41 \\
& & & & & & -52 \\
$(75)$
\end{tabular}

257:

All samples

$11-3$ to $12-3$

$13-2$ to $14-2$

$14-3$ to $17-5$

$\begin{array}{rlr}30 & -56.4 \pm 12.6 & -37.0 \\ 4 & -68.0 \pm 3.1 & -51.1 \\ 13 & -43.9 \pm 6.9 & -25.7 \\ 12 & -67.1 \pm 4.2 & -49.8\end{array}$

(equal wt/sample)

See text for discussion

of these three groupings.

Note: Mean inclinations are the arithmetic means of the $\mathrm{H} 100$ inclinations for each site. Reversed inclinations are averaged as normal at Sites 256 and 257 . Site 257 mean is based on equal weight for each core section to correct for unequal sample distribution. SF latitude and MS latitude are the paleolatitudes predicted by the reconstructions of Sclater and Fisher (in press) and McKenzie and Sclater (1971), respectively, determined graphically. Age of reconstruction is given in parentheses in m.y.B.P. 

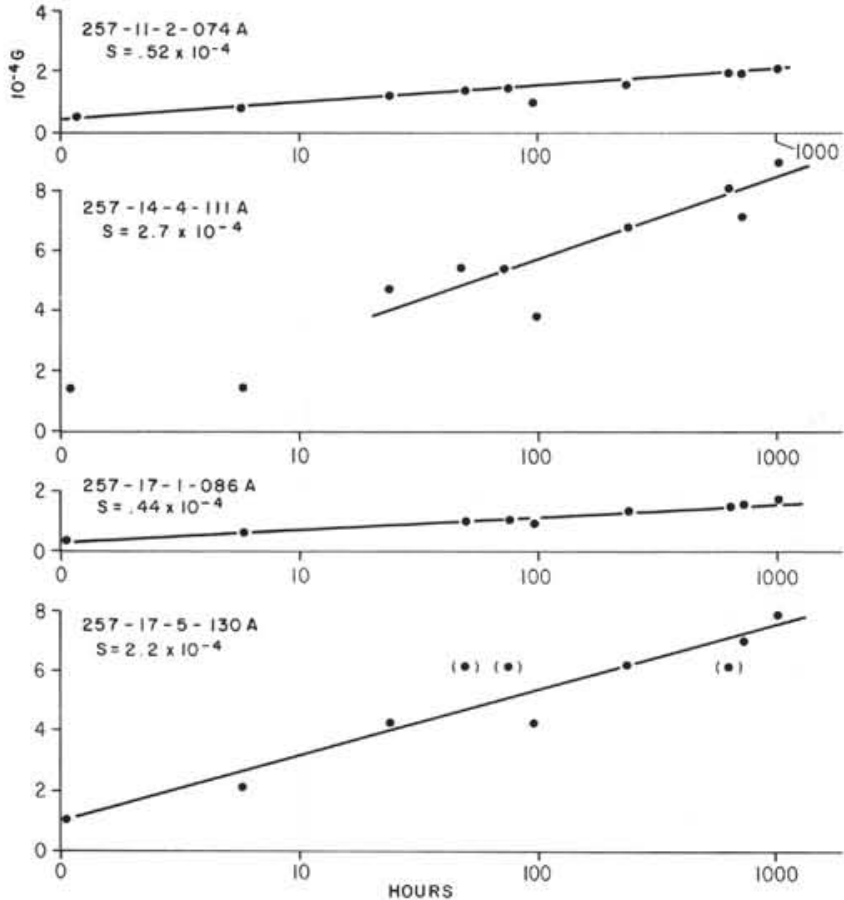

Figure 11. Viscous remanent magnetization (VRM) acquired in the earth's field by initially demagnetized specimens. VRM was calculated as the vectorial difference between the final and initial magnetic remanences. The viscosity coefficient $\mathrm{S}$ is the slope of the least-squares best-fitting line through the VRM data when plotted against the logarithm of time. During the Brunhes epoch, specimens could have acquired VRM equaling 9.78S $19.78=\log$ number of hours in 700,000 years) if the linear extrapolation is valid and initial magnetizations were zero.

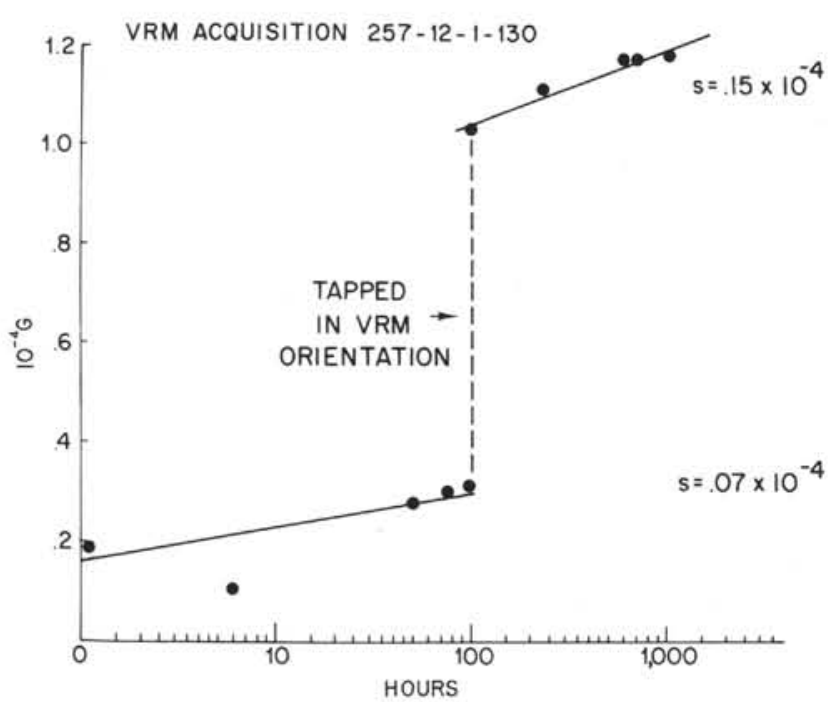

Figure 12. Shock-remanent magnetization (SRM) acquired by Sample 257-12-1, 130 when tapped in its VRM test orientation. The SRM intensity was about 3\% of NRM and was oriented in the direction of the applied earth's field.

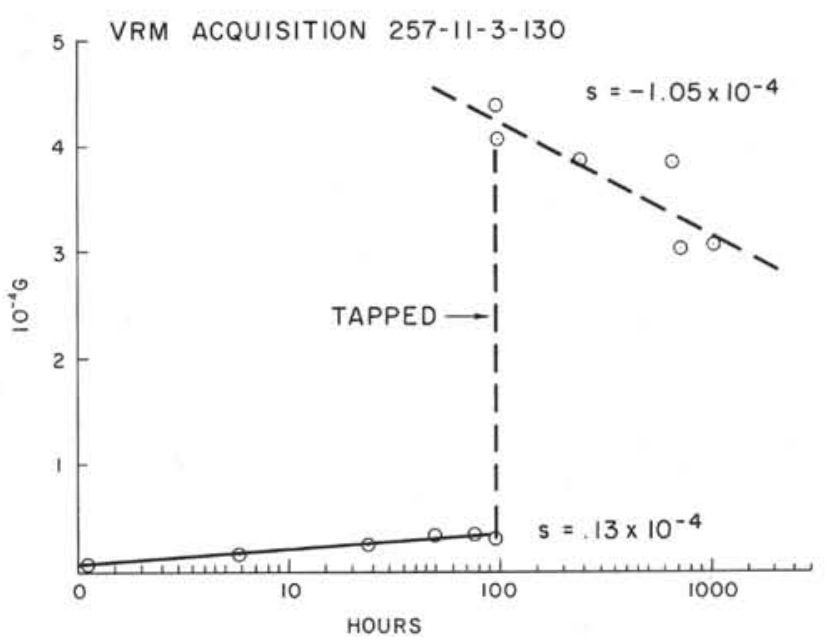

Figure 13. SRM test using Sample 257-11-3, 130, rotated away from the VRM orientation by $180^{\circ}$ in the horizontal plane. The SRM lay along the applied earth's field and was about $20 \%$ of the specimen's NRM intensity.
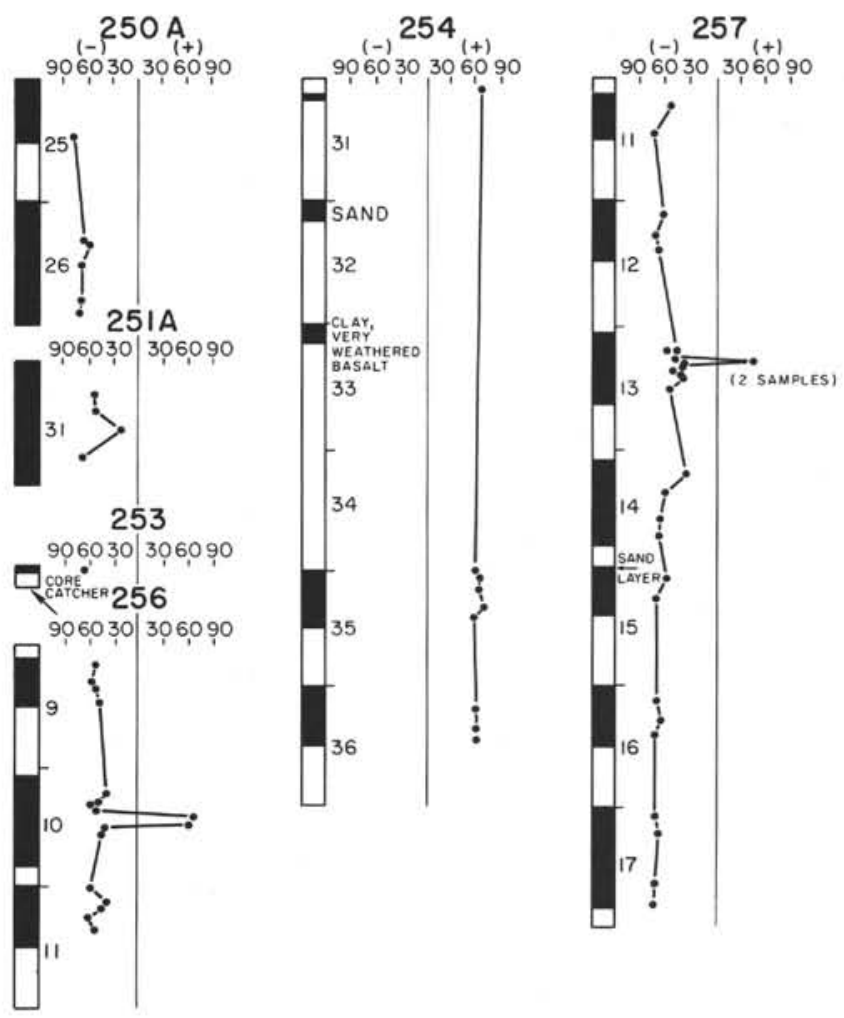

Figure 14. Magnetic inclinations versus depth for DSDP Leg 26 basalt samples after HF demagnetization at 100-oe peak. Core section numbers are adjacent to the core recovery logs (black $=$ recovery; white $=$ no recovery $)$. Since all sites are in the Southern Hemisphere, negative inclination corresponds to normal polarity. 


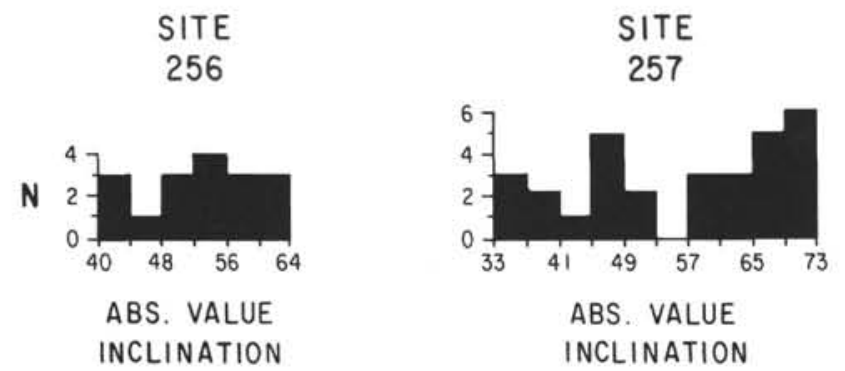

Figure 15. Histograms of magnetic inclinations for Sites 256 and 257 after AF cleaning at 100-oe. Note the bimodal distribution for Site 257. patible with the reconstructions. At Site 254 our paleolatitude falls midway between the predictions of McKenzie and Sclater (1971) and Sclater and Fisher (in press) and appears to agree with the Indian plate polar wandering curve. It should be noted, however, that no age control is available along the Tertiary portion of the curve, hence the agreement of Site 254 is not very rigorous.

The sites for which we have the most data, 256 and 257 , are both on the Australian plate, and their magnetic paleolatitudes are open to interpretation. The latitude we determined for Site 256 lies within $10^{\circ}$ of the reconstruction position, but the data must be regarded with low confidence because of the unstable behavior ex-

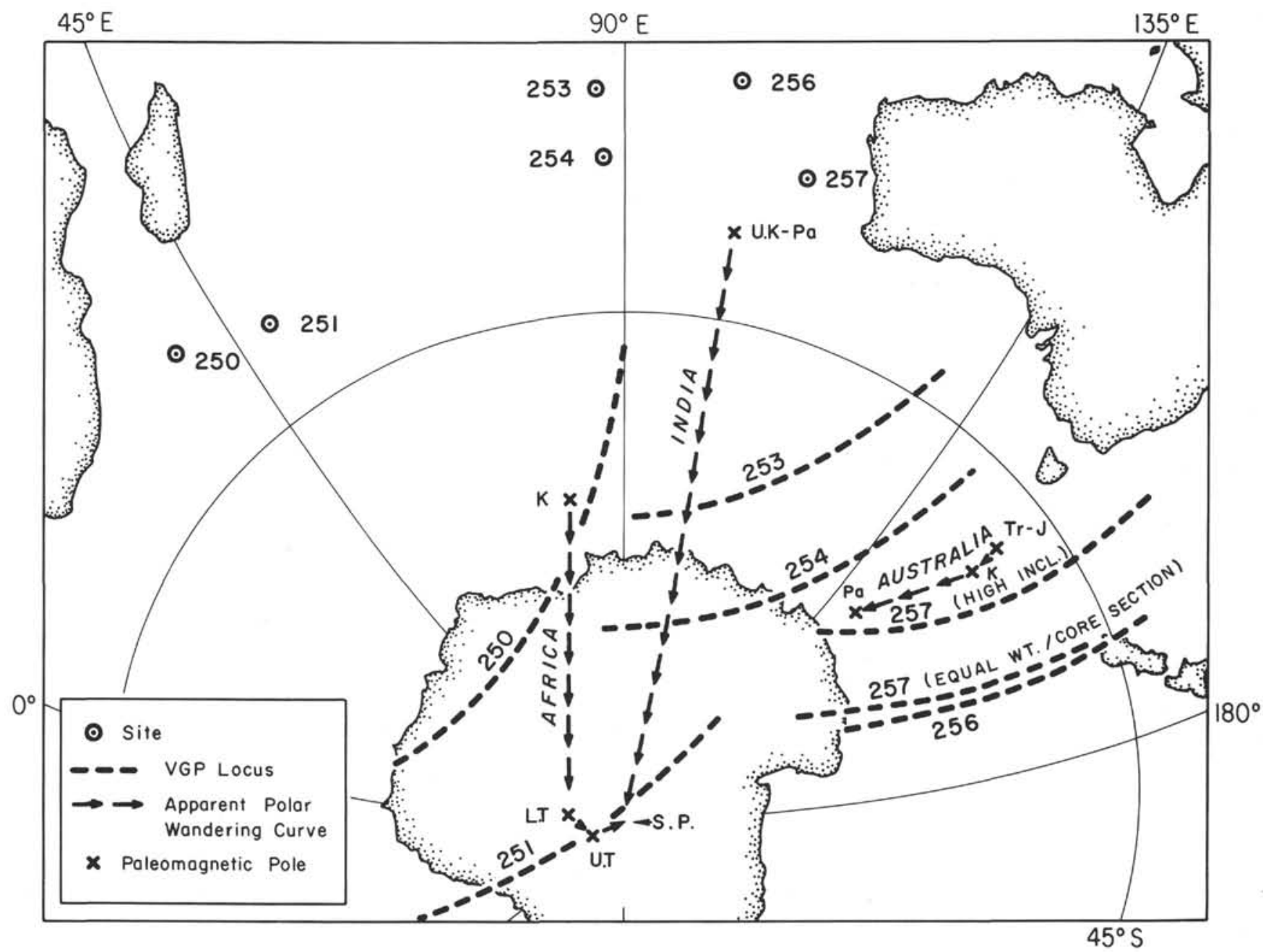

Figure 16. Loci of VGP's from DSDP Leg 26 basalts, compared with apparent polar wandering curves compiled by McElhinny (1973). Catalog numbers of data from McElhinny (1973) are:

Africa: Cretaceous (K): AF 10.1-2; Lower Tertiary (LT): AF 11.1-2; Upper Tertiary (UT): AF 12.1-4 India: Upper Cretaceous-Paleocene (UK-Pa): IN 11.2

Australia: Triassic-Jurassic (TR-J): AU 8.1, 9.1-5; Cretaceous (K): AU 10.1-2; Paleocene (Pa): AU 11.1

Error bands for the VGP loci were omitted from the diagram to avoid confusion. In the case of Site 257 (equal-weight per core section), the $\pm 1 S D$ band is $26^{\circ}$ wide and incorporates the VGP locus based on the two groups of higher inclinations. Lambert equal-area projection centered at $60^{\circ} \mathrm{S}, 90^{\circ} \mathrm{E}$. 
hibited by many of the specimens. The magnetic paleolatitude varies considerably at Site 257 , depending on the manner in which the data are averaged (Table 2). Although the group of lower inclinations at this site appears to be anomalous, we presently have no valid reason for discarding it, since its internal consistency is high. The paleolatitude determined from the two groups of higher inclinations agrees well with the reconstructions and the Jurassic-Paleocene polar wandering curve for Australia. If, however, the mean is based on equal-weight per core section, the VGP locus then lies significantly south of the Australian curve, near that of Site 256. McElhinny (in press) found a similar VGP locus for Site 259. Such an occurrence may be coincidental or it may represent motion of these sites relative to the eastern Australian localities used for determining the polar wander curves. It is worth noting that our VGP loci at Sites 256 and 257 approximately parallel the Australian Jurassic-Paleocene polar wandering curve and thus neither support nor contradict the -100 m.y. span of K/Ar ages reported by Snelling and Rundle (this volume) at Site 257.

Because of the limited (and uncertain) number of flows sampled in each Leg 26 hole, the polar wandering curve correlations observed at several of the sites may be misleading. The sediments immediately overlying the basalts could resolve some of the present ambiguities of interpretation and form a more reliable basis for the paleomagnetic reconstruction of the southern Indian Ocean.

\section{ACKNOWLEDGMENTS}

Discussions with W. Lowrie and J. M. Ade-Hall broadened our understanding of viscous remanence and magnetic mineralogy. We thank J. G. Sclater for his advice, enthusiastic encouragement, and a preprint of Sclater and Fisher (in press). The authors were supported by ONR contracts N-00014-67-A0204-0048 (J.W.P.), N00014-66-CO241 NR 083-004 (B.P.L.), and a Postdoctoral Fellowship from the Woods Hole Oceanographic Institution (C.R.D.).

\section{REFERENCES}

Fox, P. V. and Opdyke, N. D., 1973. Geology of the oceanic crust: magnetic properties of oceanic rocks: J. Geophys. Res., v. 78, p. 5139-5154.

Lowrie, W., 1973. Viscous remanent magnetization in oceanic basalts: Nature, v. 243 , p. $27-29$.

Lowrie, W., Lovlie, R., and Opdyke, N. D., 1973. The magnetic properties of Deep Sea Drilling Project basalts from the Atlantic Ocean: Earth Planet. Sci. Lett., v. 17, p. 338349.

Lowrie, W. and Opdyke, N. D., 1972. Paleomagnetism of igneous samples. In Hayes, D. E., Pimm, A. C., et al., Initial Reports of the Deep Sea Drilling Project, Volume 14: Washington (U.S. Government Printing Office), p. 1973. Paleomagnetism of igneous and sedimentary samples. In Edgar, N. T., Saunders, J. B., et al., Initial Reports of the Deep Sea Drilling Project, Volume 15: Washington (U.S. Government Printing Office), p.

McElhinney, M. W., 1973. Paleomagnetism and plate tectonics: Cambridge (Cambridge University Press). , in press. Paleomagnetism of basalt samples, Leg 27. In Heirtzler, J. R., Veevers, J. J., et al., Initial Reports of the Deep Sea Drilling Project, Volume 27: Washington (U.S. Government Printing Office).

McKenzie, D. and Sclater, J. G., 1971. The evolution of the Indian Ocean since the Late Cretaceous: Roy. Astron. Soc. Geophys. J., v. 25 , p. 437-528.

Nagata, T., 1971. Introductory notes on shock remanent magnetization and shock demagnetization of igneous rocks: Pure Appl. Geophys., v. 89, p. 159-177.

Phillips, J. D. and Kuckes, A. F., 1967. A spinner magnetometer: J. Geophys. Res., v. 72, p. 2209-2212.

Sclater, J. G. and Fisher, R. L., in press. The evolution of the east central Indian Ocean, with emphasis on the tectonic setting of the Ninetyeast Ridge: Geol. Soc. Am. Bull.

Watkins, N. D., Hajash, A. and Abranson, C. E., 1972. Geomagnetic secular variation during the Brunhes epoch in the Indian and Atlantic regions: Roy. Astron. Soc. Geophys. J., v. 28, p. 1-25. 